\title{
The Research on Cultivating Welfare Service by NGO in China Urban Community
}

\author{
$\mathrm{Lu}_{\mathrm{Jin}^{1}}^{1} \&$ Ruiming Zeng ${ }^{2}$ \\ ${ }^{1}$ School of Management, Shanghai University of Engineering Science, Shanghai, China \\ ${ }^{2}$ School of Social Science, Shanghai University of Engineering Science, Shanghai, China \\ Correspondence: Lu Jin, School of Management, Shanghai University of Engineering Science, Shanghai, ON., Long \\ Teng Road No.333, China. Tel: 86-139-1852-5665. E-mail: shirley_jin0829@126.com
}

Received: November 24, 2013 Accepted: December 6, 2013 Online Published: December 7, 2013

doi:10.5430/sass.v1n1p38 URL: http://dx.doi.org/10.5430/sass.v1n1p38

This work was supported by Shanghai Science and Technology Commission of scientific research and innovation projects. (No.12YS127).

\begin{abstract}
Within the current Chinese system of Community Welfare Services, NGO is set to become one of the main services supplier to expand the services content and meet the various needs from residents. While, the participation of NGO in public management is under the specific reform history of China especially in community welfare services. The traditional Unit welfare left many traditional welfare habit which make citizenry still keep the government relying consciousness. Despite more than 20 years of efforts, a lot of progress has been made in the Community Welfare Services. NGO development in China community is still lagging behind with the internal and external factors restrain. Therefore, in order to promote the development of community welfare services, NGO must eliminate obstacles as soon as possible to adapt to the China's environment and improve the whole social welfare.
\end{abstract}

Keywords: community welfare service, NGO, social governance, public participation

\section{Introduction}

The public sectors of China urban government has been supplied public service in China community since the opening up reform, which abolished the traditional unit social welfare system based on the employment. Recently, with the changing environment, there is an immanent contradiction occurred between the increasing service demands and overstaffing bureaucracy. More and more attention has been paid to the collaborative mechanism offered by both NGO and government. But, as a neonatal service, NGO is still in the first stage to adapt the environment, facing with a lot of practical dilemma such as independency, instability, lacking of finance and staff foundation, even fail to arise the concern from residents. Therefore, exploration should be taken to help the NGO figure out the definition, situation, advantage and disadvantage, contributing factors and resolution, through combing domestic policies and experiences, analyzing the internal and external constraints to seek the breakthrough point and develop their capacity for service providing and self-management.

\section{The Orientation of NGO Participating the Community Welfare Service in China}

With the rise of new public management movement, non-governmental organization (NGO ) receive more and more attention worldwide. It is regarded as a vehicle for the realization of civil society, NGO in the world is taking social responsibility of providing public goods. The World Bank has defined it as: to aid the poor to help the trapped, safeguard the interests of the poor, protect the environment, the provision of basic social services, or any civil society organization to promote community development. In China, the government has been assumed primary responsibility for the provision of social welfare for citizens since the traditional unit of welfare gradually split. Meanwhile, NGO is also playing an increasingly important role in community welfare services. We identify Community Welfare Service as: government, social services, organizations and communities as the principal part, on the basis of a wide range of community welfare services and facilities, using the resources within and outside the community to provide the non - profit products and services for all community residents especially the disadvantaged groups with the pursuit of enhancing the quality of life and improve social welfare (Wang. QY, 2011). The position 
of NGO in community welfare services could be defined as the following three main areas.

\subsection{Broaden the Channel of Community Welfare Services}

The subject of social welfare includes three levels: government, NGO and community residents. In China, it's also means that: according to the law, government take the main response to build a wide range organizational network through central to the local, from urban to rural. areas rule with offering the essential resources of both human and financial resources. As the same time, various professional welfare services are supplied by NGO like associations, foundations, federations, committees and other forms of associations.

\subsection{Enrich the Content of Community Welfare Services}

What kind of services could be supplied by Community Welfare Services? According to the practice in current China urban city, The existing services is limited in some specific areas like the community care for the disadvantaged groups as the elderly, the disabled, poor families, children also the community health, birth control, marriage bureau, employment agency and so on. For the narrow sense, Community Welfare Service is work for the disadvantaged groups with low viability [2]. And for broadly sense, it refers to all community residents. In that kind of situation, NGO is more hopeful to provide wide range of public welfare services, for example, Environmental Protection Agency.

\subsection{Meet the Diverse and Multilevel Needs of Residents}

The aim of Community Welfare Services is to meet the basic needs for service objects of their essential life, and where possible, to meet their demand for a higher level of spiritual and cultural development through the mutual aid in neighborhood. In order to promote the friendship between them, minimize the possible risks of their lives by mutual protection, and finally improving the social welfare in the whole community.

After understanding the connotation of four layers of Community Welfare Services, the next step we should pay attention to the exertion of NGO in the existing system of organization. Different from western countries, the Community Welfare Services in China was not be brought by the the process of industrialization. It happened a special history of regime changing which is from Units Welfare to Community Welfare. Now, NGO has been undertaken parts of the benefits originally come from the unit, but it is also restricted by this reform, which means that it has to be a passive, later, a progressive development without enough practical experiences. Therefore, it's the premise to comb the history of the reform to help us understand the present situation deeply.

\section{The Construction Track of Community Welfare Service System and NGO Participation}

In contemporary China's social transformation, further change are required to the government's administrative functions: the state - owned, collective enterprises and other units should transfer to some of the functions gradually to social community. "Unit welfare services" extremely reduced, with the increasing number of unemployed and laid-off workers, more and more people had to come back to their living place, community. Meanwhile, commodity economy is growing rapidly, pace of urbanization is accelerated. A large number of rural population pour into urban migration which expanded the total population in urban city. The traditional low level of welfare with single attendant channel does not meet the growing demand for welfare of people any more which hasten ed the parturition of NGO participation in Community Welfare Service system.

\subsection{Rise and Popularization}

In the 1980 of the 20th century, on the basis of the traditional civil service, community welfare services emerged. In 1983, the ministry proposed to mobilize forces the social welfare undertaking by a variety of channels. It defined the implementation of Community Welfare Services and its object with providing social welfare products, financial aid and services to guarantee essential life.I n 1988, the different levels of grass - roots community service system model in the national big or media-sized cities extensive pilot.In 1992, the community welfare services into the scope of the tertiary industry, and established development of industrialization of community service and industry. At the end of this year, more than $70 \%$ streets in China had carried out the community service center, building up a welfare system to the elderly, the disabled, special care and other convenience services supply.

\subsection{Consolidation and Extension}

In 1994, the Civil Service meeting in Shanghai, fuzzy understanding of Community Welfare Services had been further clarified for its dual property which is both of a non-profit professional service undertaking and specific tertiary industry.1995 the Ministry of Civil Affairs issued the "Model Urban Community Service Standards" for instructing cities and towns throughout the country. In 2000, community welfare services was identified as key development projects in community building, it must be adhered to the development of socialization and 
industrialization of direction. In 2006, the Government in community service stressed the importance of socialization once again, encouraged and supported the participation of NGO for Community Welfare Services. In 2007, eleven-five for community services planning system to make a full system requirements. And then repeatedly stressed the importance of administrative and social solidarity mechanisms at the same time.

Among these changes, reflecting the evolution trajectory of NGO for its industrialization and socialization. While, in spite of the repeatedly stress, the bureaucracy keeps its strong force on the supply of Community Welfare Services which made the NGO quickly integrated into the bureaucratic insularity after it showed up in China. Due to the deep inflection of bureaucracy on the value and administrative regulation, NGO has been confounded with government in present China community to supply the welfare service together.

\section{The Achievement of Community Welfare Services with NGO in China}

Through the unremitting efforts for more than 20 years, more mature and stable management system and operational mechanism has been established in the filed of community administration, financial supplement and human resources mobilization. The Community Welfare Services had been popularized across the country, integrated into the daily life of urban residents with the contribution of both government, NGO and citizenry. In general, after the reform of welfare services, the construction of Community Welfare Services is including 4 areas as: community awareness, service layers of administration, manpower and material resources network, and specific welfare services.

\subsection{Establishing the Welfare Consciousness from Government and Unit to Community}

In the past, when people met difficulties would first get in touch with government and their working units to get welfare resolution. Now it is guardedly replaced by subdistrict, residents' committee and other NGOs. The government has introduced a series of protect and support policies and measures on project planning, tax breaks, financial support, land and facility and the reparation of employment for creating a good operating environment for Community Welfare Services.

\subsection{Service Management System with Chinese Characteristics}

Mainly refers to the government administrative system level, through the utilization of executive power to develop policies and regulations which contribute to the management system with the headship of government, leading by Ministry of Civil Affairs, participating with NGO from social resources. The government is responsible for object planing, policies enacting, service standards drafting and supplying the projects and expenditure, guiding NGO to participate welfare services. But the administration system is followed the traditional bureaucracy, setting special institutions in municipality, district and subdistrict. At the same time, NGO is classed into the social forces usually including residents' committee, china communist youth league, woman's Federation, trade unions and other organization in community. Combing of both government and NGO forces, there comes to be a big welfare services network.

\subsection{Weaving Manpower and Material Resources Network}

First of all, capital protection mechanisms is the key point. There are 3 sources for the supply of Community Welfare Services fund: first, the government funding, both direct and indirect. The former is a financial allocation, the latter is reflected in tax breaks, free venues and facilities. The social contributions income. The community's own profit income, charging low fees on the part of the service beyond the basic needs of life to enhance the self - sustainability. Secondly, the composition and the mobilization of human resources is an essential condition for running. In recent years, China has established a dedicated team with as the backbone, with part-time staff as the mainstay, on the basis of community volunteer. To the end of 2012, the National Urban Community Services has reached 180,000, it has been built as a features complementary pattern and supportive network.

\subsection{Shifting the Welfare Service Compensative to Universal Guardedly}

Shifting service object from the elderly, the disabled, special groups such as children, preferential object extended to all community residents. Upgrading services range from a single service development of decentralized to layered and faceted systematic service including community assistance, pensions, assistive, save the lone, employment, youth, education, medical rehabilitation, residents living, housekeeping, information and security. Implement a fair and reasonable service charges, take paid, unpaid combination of approaches (Tang. J, 2002). Exerting the facility services, support services, volunteer services under diverse service channels.

\section{Barriers for NGO to Integrate Community Welfare Service System in China}

Although construction has achieved many accomplishments from it's scratch, but it's not sufficient to meet the welfare needs of the growing material and cultural development of people. More and more concern has been taken 
into NGO. While, in reality the history of NGO participation is only several years, with a serious of practical difficulties such as lack of independence, stability, capital and talent, residents concern and participation, there is a still long way to go for NGO development. Currently, two main factors, inherent and extrinsic, could be regard as the reason why NGO grow slowly in China:

\subsection{External Factors Restricting the Development of NGO}

China's NGO service local communities, is bound to the same fusion of the actual situation across the country. The external factors tend to come from the management system, differences in culture, local development and legal environment, and so on. Various practical experience in different countries has their own restriction, so it may not fit the China situation. In China, the contradictions of the external environment is as follows:

1) Administration System is still lagging behind, NGO follow the bureaucracy

Firstly, the transformation of government functions could not be reasonable, it's still keep hosting most of the community welfare services which limit NGOs' play space. Secondly, the Government does not adequately nurture the NGO on both the policy and funding, furthermore, even not trying hard enough to encourage residents and volunteers to participation the welfare services. Thirdly the Ministry of Civil Affairs has also been undertaken a number of challenges and pressures, traditional bureaucracy such as multiple management and administration privileges is badly encumbering efficiency of public management.

On the other hand, residents'committee, which hands-on most of the Community Welfare Services, is being inflected by bureaucracy too much in daily work which make it too busy to handle the residents appeal instead of administrative tasks and cause the difficulty on the autonomous cultivation

2) Low participation and recognition, NGO lack of culture atmosphere

Community Welfare Services in China is a product of driven by ideas of the reform of socialization of social welfare, but in the disintegration of the system of units welfare, during the tide market - oriented reform of separating the political and social, most of the residents remain on the inertial thinking of government, their community consciousness is weak (Jiang. LH, 2008). Their knowledge of the community is not very comprehensive. And these reasons caused the low participation and recognition.. Relying on strong sense of psychological and received, lacking of responsibility for active participation in community affairs, even misunderstand and reluctant to work in community. The modern concept of civil society still do not apply at all.

3) Restricted from differences in regional development, service level is irregular

With the increasing differentiation of social interest groups and community classes in China, different types of community began to emerge with different supply capacities and demands. Communities and vulnerable communities can be divided into advantages and disadvantages with unbalanced development. The advantages are equipped with specification of property management, perfect service facilities, good community health and environmental quality that make their residents generally feel safe. But the residents in disadvantage communities have opposite feelings. On the hierarchy of needs, the social welfare of vulnerable groups need low-level, free sex service, residents have the ability to meet the needs of self - service will be interested in the brands and quality of service. So, during the process of NGO embedding in Community Welfare Services, they have to think about how to adapt to the reality of China's urban population diversity.

4) Existing legal and regulatory norms is fuzzy, NGO protection is not enough

There is no social welfare legislation in our current country, most of the relevant legal system is made for socially vulnerable group but lack of protection strength which lead to specification deficiency. The government financial investment is always made by local leaders with subjective will which follow the impact of policy guidance and public opinion. Community Welfare Service expenditure is not included in the national budget system or other undertaking budget.The different levels of government on funding responsibility system, lacking with a clear mechanism and responsibilities will easily lead to unclear, murky issue of liability.

\subsection{Internal Factors of Restricting the Development of $N G O$}

The NGOs in current China compared with western countries are featured with small numbers, weak influence, widespread scarcity of resources, lack of capacity, low specialized level relatively and other problems. These weakness make it hard to take on heavy responsibilities for the function transfer from the government, and it is delaying the process of socialization of Community Welfare Service in China.

1) Poor financial capacity for theirselves and insufficient government investment 
Fund shortage is the critical restriction for long-term development. Community Welfare Services don't have strong autotrophy with the characteristic of public welfare. As the subject of responsibility, the investment of government is the most important assurance. While compared with western country, Chinese government investment is still relatively low percent of total expenditure, up to about $30 \%$. From the perspective of the current situation, the vast majority of revenue for government funding is used to stimulate economic growth, funding for community welfare services is very limited (Yang. T, 2000). Secondly, social sources of financing have to be transferred to the operation of society and business mechanism. Charitable donation in China at present is unstable, not enough to become an independent and stable financing.

2) Deficiency of professional talents

From a long-term perspective, composition and quality of the current community welfare services team in China is not adapt to the demands come from China's socialist market economy development.This team is still in the extensive development stage of epitaxial growth and expansion (Wang. M, 2006). The staff generally do not have good education and profession background, their salaries is low. They are always not capable enough to provide professional and high level services. Most of the staff are composed of laid-off workers, housewives, retired persons and persons with disabilities have the ability to work. And among this composition ratio of the team, full-time staff is limited. in minority. The majority is outsourcing laborer without professional social work training. In addition, the volunteers team in community is still in its infancy, need to gain experience in practice and improve volunteer management and co-ordination of the services.

\section{3) Shortage of high-level service}

In the current practice of China's Community Welfare Services, services project is not yet in a big range, and the service level is stay in basic financial support. Mostly the elderly, the disabled, poor families, community care and community health, birth controlling, marriage, employment agencies, and other content. There is till a blank of high level, high knowledge content, professional counseling service such as psychological and behavioral, counseling, mentally handicapped children counseling, the mentally handicapped counseling, adolescent behavior correction of the problem, violence in families and single-parent family counseling and treatment and so on. Moreover, even the basic services, some community may still face the insufficient supply.

\section{The Thinking of Optimizing the Community Welfare Services with NGO Exploiting}

With the continuous improvement of the socialist market economy, Community Welfare Services will be developed with it's connotation and extension. Welfare objects will also be extended from,the traditional groups of the special difficulty to the entire population. Recognize the importance of building Community Welfare Services under the new situation is a response to the needs and expectations of the citizenry. In the next practice, cooperation between NGO and government remains the main way of community welfare products supply. The improvement of Community Welfare Services will be closely related with the NGO capability, which require it should enhance its adaptability as soon as possible with the effort to reduce obstacles to internal and external factors,

\subsection{Upgrade Target Strategy for Community Welfare Services}

About goal setting, community welfare services is an important part of people's livelihood with the most extensive foundation. Therefore, the strategic upgrading of Community Welfare Services is to improve the members of the community, sharing the fruits of development to reflect on social welfare. Several basic principles should be set as: people - oriented and coordinated development, based on national circumstances, diverse participation, results sharing, shared responsibilities.

\subsection{Strengthening the Mutual Trust between NGO and Public, Promote Self-Development of NGO}

First of all, to break the traditional habit of government benefits, the government should guide residents get welfare service through the NGO in community, acting the bridge role in the selection mechanism in order to promote the self-development opportunities of NGO. Secondly, in terms of NGO personnel training, should expeditiously improve the wages and social security of employees, helping to attract talents by preferential policy and eliminate employment discrimination. These efforts will be a positive response to NGOs' social responsibility contribution and affirmation.

\subsection{Increasing Fiscal and Financial Investment, Improving Legal Regulations}

Construction of social welfare services is an important foundation for public management. Governments at all levels should strengthen the construction of Community Welfare Services into economic and social development planning, on fiscal and policy, more inclined policies should be taken in the cooperation between NGO and government and 
fostering the capacity of $\mathrm{NGO}$ in Chinese community, helping them to developed high level and high level of services adapted to contemporary society. At the same time increasing the legal status of the NGO as the subject of service supply, reducing unnecessary registration restrictions, assisting the NGO coordination with the various government departments, the relationship between enterprise to protect their legitimate rights and interests under the existing public management system..

\section{Conclusion}

Present Chinese NGOs are limited in their internal and external conditions which make it hard to meet the new demand of economic and cultural development and citizenry welfare needs. In the study on the development of NGO in China must first clear the current framework of community welfare service system of socialism with Chinese characteristics and the content, and to explore the challenges encountered in the course of their practice, thinking on the true path and countermeasures to the development of NGO in China. For the internal aspect, more policies should be taken to help NGP gain manpower and material resources. Fore the external aspect, more efforts should be put on the environment promoting by strengthening the mutual trust between public and NGO and expand their activity spaces which would increase the whole social welfare in China.

\section{References}

Jiang, L.H. (2008). The urban community welfare of China. Beijing, China: Social Sciences Academic Press.

Tang, J. (2002). Thinking of the urban community service. China Social Science, 02, 11-15.

Wang, M. (2006). Social Function and Classification of Non-profit Organizations. Academic Month, 09, 8-12.

Wang, Q. Y. (2011). Study on social welfare development in the new period in China. Beijing, China: People's Publishing House.

Yang, T. (2000). Chinese urban community service security with NGO. Chinese Management World Press. pp. 111-120. 